\title{
Detection, Quantification, and Vegetative Compatibility of Verticillium dahliae in Potato and Mint Production Soils in the Columbia Basin of Oregon and Washington
}

\author{
M. A. Omer, United States Department of Agriculture-Agricultural Research Service, Toledo, OH 43606; \\ D. A. Johnson and L. I. Douhan, Department of Plant Pathology, Washington State University, Pullman 99164; \\ P. B. Hamm, Department of Botany and Plant Pathology, Hermiston Agricultural Research and Extension Center, \\ Oregon State University, Hermiston; and R. C. Rowe, Department of Plant Pathology, The Ohio State University- \\ OARDC, Wooster 44691
}

\begin{abstract}
Omer, M. A., Johnson, D. A., Douhan, L. I., Hamm, P. B., and Rowe, R. C. 2008. Detection, quantification, and vegetative compatibility of Verticillium dahliae in potato and mint production soils in the Columbia Basin of Oregon and Washington. Plant Dis. 92:1127-1131.

Soil samples from 87 fields intended for potato production in the Columbia Basin of Washington and Oregon and 51 fields intended for mint production in Washington were assayed on a semiselective medium to quantify populations of Verticillium dahliae. The pathogen was isolated from $77(89 \%)$ of the fields intended for potato production and $41(80 \%)$ of the fields intended for mint production. Population densities ranged from 0 to 169 propagules/g of air-dried soil in fields intended for potato production and 0 to 75 propagules/g of air-dried soil in fields intended for mint production. Isolates of $V$. dahliae were recovered from soil assay plates and pure cultures were prepared to provide a collection of isolates for vegetative compatibility analysis. Among fields intended for potato production from which isolates of the fungus were assigned to a vegetative compatibility group (VCG), $93 \%$ of the fields were found to contain one or more isolates assigned to VCG 4A, nine (23\%) contained one or more isolates assigned to VCG4B, and only one (3\%) contained any isolates assigned to VCG 2B. In the case of fields planned for mint production in 1999 from which isolates of the fungus were assigned to a VCG, 13 fields (81\%) were found to contain one or more isolates assigned to VCG 4A, 7 (44\%) contained one or more isolates assigned to VCG $4 \mathrm{~B}$, and $5(31 \%)$ contained one or more isolates assigned to VCG 2B. VCG 4A isolates of $V$. dahliae are widespread and numerous, particularly following potato production, but cause only mild to moderate symptoms in mint; therefore, this pathotype is unlikely to seriously endanger subsequent plantings of mint. However, planting potato in a field recently used to produce mint may pose a significant risk to the potato crop if high populations of the VCG4A pathotype (highly aggressive to potato) predominate. Preplant assessment of soil populations of $V$. dahliae without regard for the relative populations of various pathotypes present in a particular sample may lead to information not fully useful in integrated pest management systems.
\end{abstract}

Additional keywords: Mentha, potato early dying, Solanum tuberosum

Verticillium dahliae Kleb. is a widespread soilborne fungal plant pathogen that causes vascular wilt disease on many important crops $(30,33)$. In potato (Solanum tuberosum L.), infection by $V$. dahliae, especially in the presence of the rootlesion nematode Pratylenchus penetrans, causes potato early dying (PED; 31,33). PED leads to early decline of potato foliage and can result in a substantial reduction in yield and tuber size $(7,31,33)$. In North America, yields can be reduced 10 to $15 \%$ in moderately infested fields and 30 to $50 \%$ in heavily infested fields (33). Effective management strategies for PED

Corresponding author: R. C. Rowe

E-mail: rowe.4@osu.edu

Accepted for publication 8 February 2008.

doi:10.1094/PDIS-92-7-1127

(C) 2008 The American Phytopathological Society use various crop rotations, cultivar resistance, and, sometimes, preplant soil fumigation (4,33). V. dahliae survives in soil as microsclerotia that form in the decaying tissues of infected host crops $(26,34)$. Because microsclerotia are the primary overwintering inoculum of $V$. dahliae, detecting the presence and populations of microsclerotia in soils targeted for potato production is important in disease risk assessment. A direct relationship between inoculum density of $V$. dahliae in soil, wilt severity, or stem colonization (4) and tuber yield $(11,28)$ has been shown in potato. Disease threshold values for potato have been demonstrated to be in the range of 5 to $30 \mathrm{CFU} / \mathrm{cm}^{3}$ of air-dried soil for $V$. dahliae microsclerotia alone and as low as 2 to $13 \mathrm{CFU} / \mathrm{cm}^{3}$ of air-dried soil for $V$. dahliae microsclerotia in the presence of $P$. penetrans $(14,31)$. Determining preplant populations of $V$. dahliae in soil can be a useful tool in selecting fields that are either safe for planting potato or that may benefit from specific disease management procedures. A direct relationship between $V$. dahliae inoculum density and disease incidence and severity also has been reported for several other crops $(1-3,5,23)$.

Peppermint (Mentha $\times$ piperita L.) and Scotch spearmint (Mentha $\times$ gracilis Sole), two of the three mint species produced commercially for essential oils in the western and midwestern United States, are both highly susceptible to infection by $V$. dahliae $(8,17)$. Native spearmint (Mentha spicata $\mathrm{L}$.) can be infected by $V$. dahliae but is less susceptible to wilt damage than the other two species $(8,18)$. However, the oil of this species has more limited commercial use and, thus, it is not as desirable a crop. Verticillium wilt of mint is characterized by chlorosis of foliage and stunting and mortality of plants $(8,12)$. Initial inoculum of $V$. dahliae in mint consists of microsclerotia present in soil prior to planting rhizomes to establish a new mint field, or planting of rhizomes already infected with the pathogen $(21,34)$. Management of Verticillium wilt in peppermint and Scotch spearmint is focused primarily on planting mint rhizomes free of $V$. dahliae into noninfested soil (27). Fields already infested with the pathogen usually are not suitable for production of these two mint species. Other management strategies, which usually are only partially or temporarily effective, include stubble flaming, limited tillage, crop rotation, deep plowing, and fumigation $(9,10,13,25)$. Lacy and Horner (20) showed that severe wilt symptoms and yield loss could occur in peppermint at 10 CFU/g of soil, a disease threshold similar to potato.

In the Columbia Basin of eastern Washington and northeastern Oregon, all three mint species commonly are grown in proximity to or in rotation with potato. Mint is produced on about 13,200 ha in this bistate region, and approximately half of the mint fields are grown in rotation with potato. Conversely, approximately $10 \%$ of the 65,000 ha of potato grown in the Columbia Basin are cropped in rotation with mint. Effects of mint production on soil populations of $V$. dahliae and how these populations affect subsequent potato crops, or vice versa, have been investigated only recently (8). 
The widespread use of vegetative compatibility analysis $(22,32)$ to define distinct subspecific groups of isolates within $V$. dahliae has led to recognition that hostadapted pathotypes of $V$. dahliae exist that are more aggressive to potato $(15,31)$ and mint $(8,18)$ as well as cotton (6) and several other crops $(19,30)$. Douhan and Johnson (8) found that isolates of $V$. dahliae collected from infected mint plants growing in the western and midwestern United States nearly all belonged to vegetative and Santo (18) showed that VCG 2B isolates were more aggressive to mint than those in VCG 4A. It is well documented that isolates infecting potato are almost exclusively in VCG 4A and VCG 4B (29) and that VCG 4A isolates are the most aggressive to potato $(15,31,33)$. Furthermore, synergistic interactions of $V$. dahliae with $P$. penetrans have been shown to occur in peppermint and Scotch spearmint with VCG 2B (18) but in potato with VCG 4A $(14,31)$. Given the existence of hostcompatibility group (VCG) 2B. Johnson

adapted pathotypes of $V$. dahliae and their different pathogenic interactions among specific crops, questions can be raised regarding the utility of preplant soil assays to enumerate soil populations of this pathogen as part of a management program. Information about the VCG composition of the populations that are being detected may provide a clearer indication of the potential pathogenicity and aggressiveness of $V$. dahliae to a crop intended for planting rather than mere numerical estimates of overall soil population density.

The objectives of this study were to (i) extensively sample soils from commercial production fields throughout the Columbia Basin prior to planting either potato or mint in these fields and determine the populations of $V$. dahliae propagules in these samples, and (ii) isolate pure cultures of $V$. dahliae from representative colonies of the fungus recovered from these soil samples and determine the VCG of each isolate. The goal was to determine the

Table 1. Isolation and characterization of Verticillium dahliae from soil samples collected in 1997 from fields intended for potato production in 1998 in the Columbia Basin of Washington and Oregon

\begin{tabular}{|c|c|c|c|c|c|c|}
\hline \multirow[b]{2}{*}{ Location $^{\mathbf{a}}$} & \multicolumn{3}{|c|}{ No. of fields } & \multicolumn{3}{|c|}{ No. of fields identified with } \\
\hline & Sampled & Detected $^{b}$ & Recovered $^{\mathrm{c}}$ & VCG 4A & VCG 4B & VCG 2B \\
\hline \multicolumn{7}{|c|}{ Upper Columbia Basin } \\
\hline George & 17 & 14 & 4 & 4 & 0 & 0 \\
\hline Mattawa & 5 & 4 & 1 & 0 & 1 & 0 \\
\hline Moses Lake & 10 & 8 & 5 & 5 & 1 & 0 \\
\hline Royal City & 6 & 4 & 4 & 4 & 2 & 0 \\
\hline Quincy & 5 & 5 & 2 & 2 & 0 & 0 \\
\hline Othello & 1 & 0 & 0 & 0 & 0 & 0 \\
\hline Ephrata & 1 & 1 & 1 & 0 & 0 & 1 \\
\hline Totals & 45 & 36 & 17 & 15 & 4 & 1 \\
\hline \multicolumn{7}{|c|}{ Middle Columbia Basin } \\
\hline Pasco & 1 & 1 & 1 & 1 & 0 & 0 \\
\hline Prosser & 2 & 2 & 2 & 2 & 1 & 0 \\
\hline Totals & 3 & 3 & 3 & 3 & 1 & 0 \\
\hline \multicolumn{7}{|c|}{ Lower Columbia Basin } \\
\hline Hermiston, OR & 20 & 20 & 10 & 9 & 4 & 0 \\
\hline Patterson & 19 & 18 & 10 & 10 & 0 & 0 \\
\hline Totals & 39 & 38 & 20 & 19 & 4 & 0 \\
\hline Grand totals & 87 & 77 & 40 & 37 & 9 & 1 \\
\hline
\end{tabular}

${ }^{a}$ Town nearest to sampled field. All fields in Washington except those near Hermiston, OR.

b Number of fields from which V. dahliae was detected.

${ }^{\mathrm{c}}$ Number of fields from which isolates were recovered for vegetative compatibility group (VCG) testing.

Table 2. Isolation and characterization of Verticillium dahliae from soil samples collected in 1998 from fields intended for mint production in 1999 in the Columbia Basin of Washington

\begin{tabular}{lcccccccc}
\hline & \multicolumn{3}{c}{ No. of fields } & & \multicolumn{3}{c}{ No. of fields identified with } \\
\cline { 2 - 3 } \cline { 6 - 8 } Location $^{\mathbf{a}}$ & Sampled $^{n}$ & Detected $^{\mathbf{b}}$ & Recovered $^{\mathbf{c}}$ & & VCG 4A & VCG 4B & VCG 2B \\
\hline Ephrata & 1 & 1 & 0 & & 0 & 0 & 0 \\
George & 15 & 11 & 5 & & 5 & 1 & 2 \\
Royal City & 21 & 19 & 9 & & 7 & 6 & 1 \\
Vantage & 2 & 2 & 1 & & 1 & 0 & 1 \\
Beverly & 2 & 2 & 1 & & 0 & 0 & 1 \\
Othello & 2 & 2 & 0 & & 0 & 0 & 0 \\
White Swan & 8 & 4 & 0 & & 0 & 0 & 0 \\
Totals & 51 & 41 & 16 & & 13 & 7 & 5 \\
\hline
\end{tabular}

a Town nearest to sampled field.

${ }^{\mathrm{b}}$ Number of fields from which $V$. dahliae was detected.

${ }^{\mathrm{c}}$ Number of fields from which isolates were recovered for vegetative compatibility group (VCG) testing. prevalence of specific VCGs of $V$. dahliae in soils to be cropped to potato or mintinformation that would be useful in the development of improved Verticillium wilt management strategies for these two crops in the Columbia Basin.

\section{MATERIALS AND METHODS}

Collection and preparation of soil samples. In September and October 1997, soil samples were collected randomly from 87 commercial fields in the Columbia Basin of Washington and Oregon that were intended for potato production in 1998 (Table 1). Among these fields, 68 had been used for potato production within the past 5 years, 2 had been in mint production within the past 5 years, and 1 had produced mint 15 years earlier; the remainder had been in various other crops within the past 5 years. Fields were selected from the upper, middle, and lower areas of the Columbia Basin in Washington and the lower Columbia Basin near Hermiston, OR in order to reflect the region's variable geography, soil type, and cropping history. Each sample was obtained by inserting a 2.5-cm-diameter soil auger to a depth of approximately $15 \mathrm{~cm}$. Thirty soil cores were taken randomly while walking along a serpentine pattern through each field. Cores from each field were bulked and mixed as a single sample immediately after collection and designated by a field number. All samples were air dried in paper bags for 2 to 4 weeks at approximately $50 \%$ relative humidity and $23^{\circ} \mathrm{C}$ to eliminate viable propagules sensitive to desiccation. Samples then were passed through a coarse sieve to remove dirt clods, stones, and organic debris, and stored in new plastic screw-top bottles at $4^{\circ} \mathrm{C}$ until assayed.

A second set of soil samples was collected in October and November 1998 from 51 commercial fields in the Columbia Basin of Central Washington (Table 2) that were to be planted with either peppermint or Scotch spearmint crops in 1999. Among these fields, 45 had been used within the past 19 years for either spearmint or peppermint production and 6 had not been used previously for mint production. Of the 51 fields, 30 previously had been used for potato production within the last 13 years. Four of the fields had not been used previously to grow either potato or mint. Fields again were selected to represent variability in geography, soil type, and cropping history. Soil samples were collected as above, bulked for each individual field, and then each bulked sample was spread on a greenhouse bench and air dried for 1 month. Greenhouse temperatures ranged from 22 to $26^{\circ} \mathrm{C}$ (day) and 19 to $21^{\circ} \mathrm{C}$ (night), and relative humidity was $<50 \%$. Greenhouse fans were not directed at samples and samples were shielded from air currents with 5-cm-high plastic barriers to avoid cross contamination among samples. After drying, each bulked sample was 
mixed, passed through a coarse sieve, collected on a surface-disinfested plastic container, and placed into individual autoclaved plastic screw-top bottles. Samples were stored at $4^{\circ} \mathrm{C}$ until assayed.

Determination of populations of $V$. dahliae in soil samples and collection of isolates. Dried soil samples were assayed for $V$. dahliae propagules by dilution plating directly onto NP-10 agar medium which is semiselective for Verticillium spp. Contents of the medium per liter were $5 \mathrm{~g}$ of polygalacturonic acid-sodium salt, $1 \mathrm{~g}$ of $\mathrm{KNO}_{3}, 1 \mathrm{~g}$ of $\mathrm{KH}_{2} \mathrm{PO}_{4}, 0.5 \mathrm{~g}$ of $\mathrm{KCl}, 0.5$ $\mathrm{g}$ of $\mathrm{MgSO}_{4} \cdot 7 \mathrm{H}_{2} \mathrm{O}, 0.5 \mathrm{ml}$ of Tergitol NP$10,0.05 \mathrm{~g}$ of streptomycin sulfate, $0.05 \mathrm{~g}$ of chlorotetracyclin $\mathrm{HCl}, 0.05 \mathrm{~g}$ of chloramphenicol, and $15 \mathrm{~g}$ of agar (24). Contents of each plastic bottle were shaken manually to assure complete mixing and then 10-g subsamples were removed (five for potato soils and four for mint soils). Each subsample of soil was placed in a 250-ml Erlenmeyer flask containing $90 \mathrm{ml}$ of autoclaved $0.1 \%$ water agar and the suspension was stirred for 2 min on an electric stir plate. While stirring, 1-ml aliquots were removed with a pipette and evenly spread onto individual petri dishes containing NP-10 medium. In all, 5 replicate plates were used for each subsample, for a total of 25 plates per potato soil sample and 20 per mint soil sample. Petri plates containing soil samples were incubated for 14 to 21 days at 21 to $23^{\circ} \mathrm{C}$ in the dark to allow Verticillium propagules to germinate and develop into colonies. Following 2 to 3 weeks of incubation, the surface of each plate was washed gently under running tap water to remove soil residues and plates were examined under a dissecting microscope. Colonies on each plate that were morphologically characteristic of $V$. dahliae were identified and counted. The average number of colonies per plate was used to calculate an estimate of the population density of $V$. dahliae in the soil collected from each sampled field.

After all $V$. dahliae colonies were counted, one to five colonies from each subsample were selected and subcultured in order to recover isolates of the fungus for VCG analysis. Colonies were selected that were fairly well separated from other soil debris on the plate and, thus, most likely to yield a contamination-free culture. A tiny piece of agar with microsclerotia was removed from each selected colony and transferred to a new NP-10 plate. After new colonies developed on these plates, further transfers were made onto NP-10 plates until several colonies that appeared to be uncontaminated were recovered from each subsample from as many sampled fields as possible. Transfers from these colonies then were made to individual potato dextrose agar (PDA) plates to confirm that they were uncontaminated by other microorganisms. One colony per subsample that proved to be free of contamination on the PDA plates then was selected as a bulk isolate for VCG testing. A monoconidial isolate was obtained from each bulk isolate by plating a serial dilution of a conidial suspension from each colony onto PDA and selecting an individual viable conidium.

Vegetative compatibility analysis of isolates. Monoconidial isolates of $V$. dahliae obtained from subsamples of soil collected from both potato and mint fields were tested to identify the VCG to which each belonged. A nitrate-nonutilizing (nit) mutant was prepared from each monoconidial isolate and then paired with appropriate VCG tester strains using the methods described by Omer et al (29), which were modified only slightly from those first described by Joaquim and Rowe (14). When a nit mutant of an isolate successfully formed a complementary heterokaryon with a specific tester, the isolate was assigned to the corresponding VCG.

\section{RESULTS}

Recovery of $\boldsymbol{V}$. dahliae from soil samples. V. dahliae was detected in soil collected from 77 of the 87 sampled fields $(89 \%)$ that were intended for potato production in 1998 (Table 1). Population densities of the pathogen were found to range from 0 to 169 propagules per gram of airdried soil (ppg). Among these fields, 37\% had 10 ppg or more-a population density threshold likely to cause significant incidence of PED and associated yield reduction $(11,31)$. A total of $6 \%$ of the fields had population densities of $V$. dahliae that exceeded 30 ppg (Fig. 1). Commercial fields sampled in this study were located in the upper, middle, or lower regions of the Columbia Basin (Table 1). In the upper Columbia Basin, where 45 commercial fields were sampled, $V$. dahliae was detected in 36 fields. Of these, $67 \%$ had population densities $<10 \mathrm{ppg}, 24 \%$ had 10 to $20 \mathrm{ppg}$, and $9 \%$ had $>20 \mathrm{ppg}$. Only three fields from the middle Columbia Basin were sampled and $V$. dahliae was detected in all three. One had a population density $<10$ ppg and two had densities between 10 and $20 \mathrm{ppg}$. Among the 39 commercial fields sampled in the lower Columbia Basin, $V$. dahliae was detected in all but one. Of these, $59 \%$ had population densities $<10 \mathrm{ppg}, 26 \%$ had 10 to $20 \mathrm{ppg}$, and $15 \%$ had $>20$ ppg.

$V$. dahliae was detected in soil collected from 41 of the 51 sampled fields $(80 \%)$ that were intended for mint production in 1999 (Table 2). Population densities of the pathogen were found to range from 0 to 75 ppg of air-dried soil. Among these fields, $33 \%$ had 10 ppg or more and $20 \%$ had population densities of $V$. dahliae that exceeded 30 ppg (Fig. 1). V. dahliae was detected in only one of the four fields that had not been used previously to grow mint or potato. Population density of V. dahliae in this field was 1 ppg of air-dried soil.

Vegetative compatibility analyses. In all, 96 nit mutants of $V$. dahliae were generated from isolates of the fungus recovered from one to five subsamples of soil obtained from each of the 40 fields planned for potato production in 1998 . Among these fields, 37 (93\%) were found to contain one or more isolates of the fungus assigned to VCG 4A, $9(23 \%)$ con-

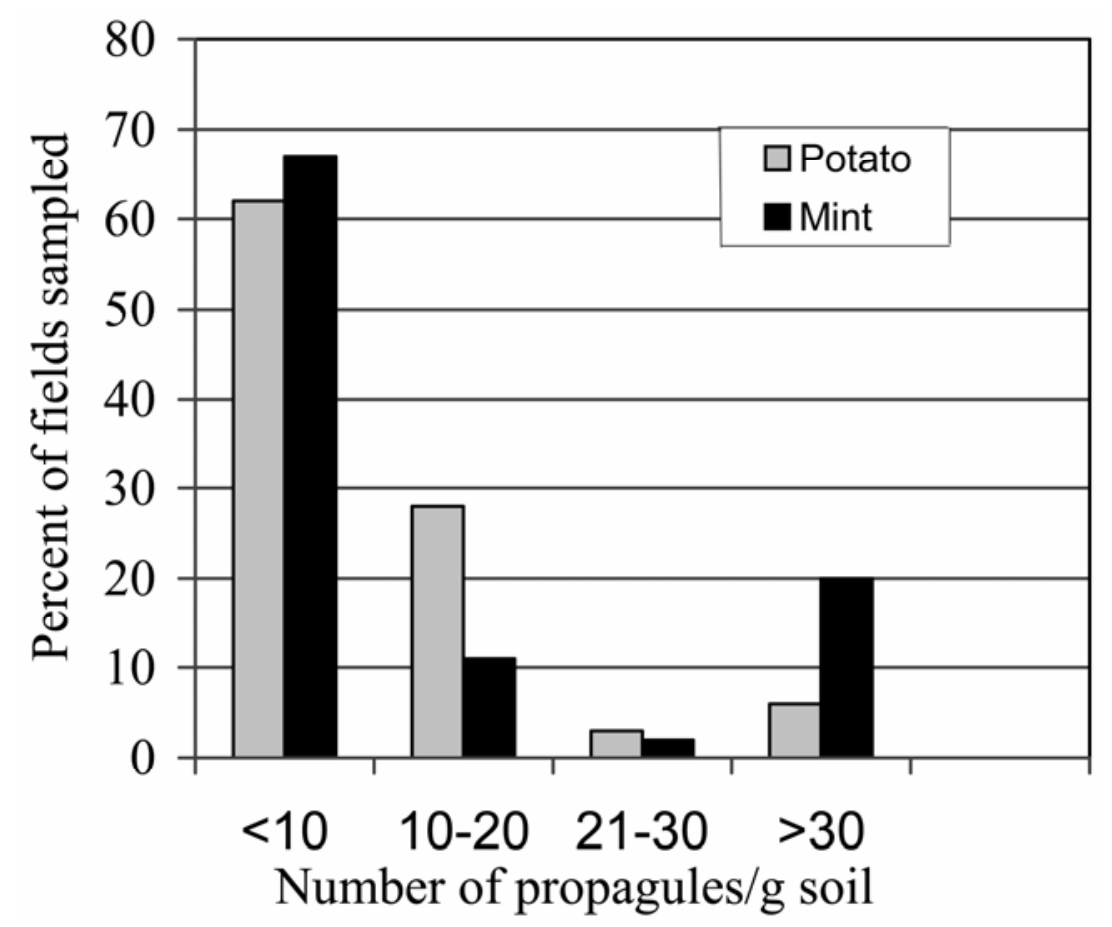

Fig. 1. Population densities of Verticillium dahliae propagules in soil samples collected from fields intended for potato and mint production in the Columbia Basin of Washington and Oregon. 
tained one or more isolates assigned to VCG 4B, and only $1(3 \%)$ contained any isolates assigned to VCG $2 \mathrm{~B}$ (Table 1). In the case of fields planned for mint production in 1999, 61 nit mutants of V. dahliae were generated from isolates of the fungus recovered from one to five subsamples of soil obtained from each of 16 fields. Among these fields, $13(81 \%)$ were found to contain one or more isolates of the fungus assigned to VCG 4A, 7 (44\%) contained one or more isolates assigned to VCG $4 \mathrm{~B}$, and $5(31 \%)$ contained one or more isolates assigned to VCG 2B (Table 2 ). The VCG could not be determined for the isolate collected from the field that had not been used previously to grow either mint or potato.

\section{DISCUSSION}

This study was undertaken to determine the prevalence and population densities of $V$. dahliae in commercial production soils in the Columbia Basin of Washington and Oregon prior to planting crops of either potato or mint and to determine which VCGs of the pathogen were present. Although fields were selected for sampling without regard to prior history of Verticillium wilt, there is no doubt that $V$. dahliae is widespread in Columbia Basin soils involved in production of both these crops. The pathogen was recovered from $86 \%$ of all soil samples collected and, in both years, about a third of the sampled fields had soil populations that exceeded $10 \mathrm{ppg}$, an action threshold above which significant damage is likely to occur in both crops $(11,20,31)$. This same pattern was found in fields planned for potato production that were sampled in all three geographic areas of the Columbia Basin. Crop history records showed that, of the 87 fields sampled that were to be planted to potato, $68(78 \%)$ had been used for potato production in the previous 5 years. Among these fields, two had been used to produce mint in the previous 5 years and one had been in mint 13 years earlier. Crop history records of the 51 fields sampled that were to be planted to mint showed that $45(88 \%)$ had been used to produce mint within the previous 19 years and $30(59 \%)$ had been in potato in the previous 13 years. Other crops produced in these 138 fields included alfalfa, wheat, sweet corn, and various vegetable crops that are not susceptible to vascular wilt caused by $V$. dahliae. The finding that $V$. dahliae was widespread in these fields was not surprising given their long-term use for production of one or both of these highly susceptible crops. Microsclerotia of the pathogen are produced abundantly in necrotic tissues of both potato and mint and are released into soil as residues of these tissues degrade $(16,21,26,33,34)$. Microsclerotia of $V$. dahliae can remain viable in soil for at least 10 years (34) and, in addition, soil populations of the pathogen can be main- tained over time on the roots of some nonhost plants $(30,33)$.

Of necessity, growers producing either potato or mint must be concerned about the inoculum of $V$. dahliae present in production fields prior to planting either of these crops. Selection of production fields, preplant decisions on the use of expensive soil fumigation treatments, and the selection of resistant cultivars often have been guided by various soil assay techniques designed to assess the population density of $V$. dahliae (35). However, it has been well established that host-adapted pathotypes exist within populations of $V$. dahliae and this may complicate such assays. Vegetative compatibility analysis has been used to identify strains that are highly aggressive to potato $(15,29)$, mint $(8,18)$, and several other crops $(6,19)$. Both potato and mint are vegetatively propagated crops with a single aggressive pathotype of $V$. dahliae predominating on each. It is likely that this pattern is maintained when the host is a crop that is reproduced clonally. In potato, VCG $4 \mathrm{~A}$ is the most aggressive pathotype causing severe disease symptoms. Strains in VCG 4B and VCG 2 are capable of infecting potato but result in generally mild to moderate symptoms (15). Douhan and Johnson (8) showed that VCG 2B was the most aggressive pathotype infecting mint. Conversely to the situation with potato, they found that isolates of VCG 4A from mint, potato, and other crops were capable of infecting mint but caused only mild to moderate symptoms. Vegetative compatibility analysis of the isolates of $V$. dahliae that we tested from Columbia Basin soils planned for potato production revealed that $93 \%$ were in VCG $4 \mathrm{~A}$, the pathotype most aggressive on potato. However, in the fields planned for mint production, $81 \%$ of the isolates were also in VCG 4A. The pathotype most aggressive on mint, VCG $2 \mathrm{~B}$, was found in only $3 \%$ of the fields planned for potato production but in $31 \%$ of those planned for mint production.

Although it is difficult to draw definitive conclusions from this data regarding the risk that these two crops pose to each other in rotation with regard to infection by $V$. dahliae, it appears that prior potato production in a field is not likely to seriously endanger future plantings of mint because VCG 2B isolates were rarely found in fields where potato commonly had been grown. It may be that that pathotype does not survive well in a soil where potato is the commonly grown Verticillium spp.susceptible crop. Isolates of VCG $2 \mathrm{~B}$ more commonly were found in soils where mint had been cropped, but even these soils generally were dominated by VCG 4A. Potato crops previously had been grown in over half of the sampled fields intended for mint production and the $4 \mathrm{~A}$ pathotype likely increased substantially when potato was grown. It also may be that the $4 \mathrm{~A}$ pathotype can maintain itself well on mint plants despite not causing significant damage to that crop. Thus, planting potato in a field recently used to produce mint may pose a significant risk to the potato crop if populations of the VCG 4A pathotype are at high populations.

It is clear from these data that preplant assessment of soil populations of $\mathrm{V}$. dahliae without regard to the relative populations of various pathotypes that may be present in a particular sample could lead to information not fully useful in integrated pest management systems. A simple determination of the total population of $V$. dahliae could overestimate the actual disease potential, particularly when planning to grow mint where VCG $4 \mathrm{~A}$ strains are not the issue (8). Current soil assay procedures based on soil plating techniques (35) do not yield information on the relative populations of various pathotypes in a given sample; therefore, new DNA-based soil assay technologies are needed that have this capability. This would facilitate the development of more precise information that could be used as an effective management tool for Verticillium wilt in either crop (33), possibly leading to reduced or more efficient use of control measures such as soil fumigants (11).

\section{ACKNOWLEDGMENTS}

This work was supported partially by grants from the Washington State Potato Commission and the Washington Mint Commission, and funding from the Ohio Agricultural Research and Development Center, The Ohio State University.

\section{LITERATURE CITED}

1. Ashworth, L. J., Jr., Huisman, O. C., Harper, M. D., and Stromberg, L. K.1979. Verticillium wilt of tomato: influence of inoculum density and root extension upon disease severity. Phytopathology 69:490-492.

2. Ashworth, L. J., Jr., Huisman, O. C., Harper, M. D., Stromberg, L. K., and Basset, D. M.. 1979. Verticillium wilt disease of cotton: influence of inoculum density in the field. Phytopathology 69:483-489.

3. Ashworth, L. J., Jr., and Zimmerman, G. 1976. Verticillium wilt of the pistachio nut tree: occurrence in California and control by soil fumigation. Phytopathology 66:1449-1451.

4. Bae, J., Atallah, Z. K., Jansky, S. H., Rouse, D. I., and Stevenson, W. R. 2007. Colonization dynamics and spatial progression of Verticillium dahliae in individual stems of two potato cultivars with differing responses to potato early dying. Plant Dis. 91:1137-1141.

5. Berbegal, M., Ortega, A., Garcia-Jimenez, J., and Armengol, J. 2007. Inoculum densitydisease development relationship in Verticillium wilt of artichoke caused by Verticillium dahliae. Plant Dis. 91:1131-1136.

6. Daayf, F., Nicole, M., and Geiger, J.-P. 1995 Differentiation of Verticillium dahliae populations on the basis of vegetative compatibility and pathogenicity on cotton. Eur. J. Plant Pathol. 101:69-79.

7. Davis, J. R., and Everson, D. O. 1986. Relation of Verticillium dahliae in soil and potato tissue, irrigation method, and N-fertility to Verticillium wilt of potato. Phytopathology 76:730-760.

8. Douhan, L. I., and Johnson, D. A. 2001. Vegetative compatibility and pathogenicity of Verticillium dahliae from spearmint and peppermint. Plant Dis. 85:297-302. 
9. Green, R. J. 1958. "Deep plowing" for controlling Verticillium wilt of mint in muck soils. Phytopathology 48:575-577.

10. Green, R. J. 1967. Control of Verticillium wilt of peppermint by crop rotation sequences. Plant Dis. Rep. 51:449-453.

11. Hamm, P. B., Ingham, R. E., Jaeger, J. R., Swanson, W. H., and Volker, K. C. 2003. Soil fumigant effects on three genera of potential soilborne pathogenic fungi and their effect on potato yield in the Columbia Basin of Oregon. Plant Dis. 87:1449-1456.

12. Horner, C. E. 1954. Pathogenicity of Verticillium isolates to peppermint. Phytopathology 44:239-242.

13. Horner, C. E., and Dooley, H. L. 1966. Control of Verticillium wilt of peppermint by soil fumigation. Plant Dis. Rep. 50:97-100.

14. Joaquim, T. R., and Rowe R. C. 1990. Reassessment of vegetative compatibility relationships among strains of Verticillium dahliae using nitrate-nonutilizing mutants. Phytopathology 80:1160-1166.

15. Joaquim, T. R., and Rowe, R. C. 1991. Vegetative compatibility and virulence of strains of Verticillium dahliae from soil and potato plants. Phytopathology 81:552-558.

16. Joaquim, T. R., Smith, V. L., and Rowe, R. C. 1988. Seasonal variation and effects of wheat rotation on populations of Verticillium dahliae Kleb. in Ohio potato fields soils. Am. Potato J. 65:439-47.

17. Johnson, D. A., and Cummings, T. F. 2000. Evaluation of mint mutants, hybrids, and fertile clones for resistance to Verticillium dahliae. Plant Dis. 84:235-238.

18. Johnson, D. A., and Santo, G. S. 2001. Development of wilt in mint in response to infection by two pathotypes of Verticillium dahliae and co-infection by Pratylenchus penetrans. Plant Dis. 85:1189-1192.

19. Katan, T. 2000. Vegetative compatibility in populations of Verticillium-an overview. Pages 69-86 in: Advances in Verticillium Research and Disease Management. E. C. Tjamos, R. C. Rowe, J. B. Heale, and D. R. Fravel, eds. American Phytopathological Society Press, St. Paul, MN

20. Lacy, M. L., and Horner, C. E. 1965. Verticillium wilt of mint: Interactions of inoculum density and host resistance. Phytopathology 55:1176-1178.

21. Lacy, M. L., and Horner, C. E. 1966. Behavior of Verticillium dahliae in the rhizosphere and on roots of plants susceptible, resistant, and immune to wilt. Phytopathology 56:427-430.

22. Leslie, J. F. 1993. Fungal vegetative compatibility. Annu. Rev. Phytopathol. 31:127-150.

23. Lopez-Escudero, F. J., and Blanco-Lopez, M. A. 2007. Relationship between the inoculum density of Verticillium dahliae and the progress of Verticillium wilt of olive. Plant Dis. 91:1372-1378.

24. Martin, M. J., Riedel, R. M., and Rowe, R. C. 1982. Verticillium dahliae and Pratylenchus penetrans: interactions in the early dying complex of potato in Ohio. Phytopathology 72:640-644.

25. McIntyre, J. L., and Horner, C. E. 1973. Inactivation of Verticillium dahliae in peppermint stems by propane gas flaming. Phytopathology 63:172-175.

26. Mol, L., and Scholte, K. 1995. Formation of microsclerotia of Verticillium dahliae Kleb. on various plant parts of two potato cultivars. Potato Res. 38:143-150.

27. Morrell, A., Schreiber, A., and Lundy, R. 1997. Pests, Pest Control and Fertilizer Use in Wash- ington Mint. Washington State University Cooperative Extension, MISC0188, Pullman.

28. Nnodu. E. C., and Harrison, M. D. 1979. The relationship between Verticillium albo-atrum inoculum density and potato yield. Am. Potato J. 56:11-25.

29. Omer, M. A., Johnson, D. A, and Rowe, R. C. 2000. Recovery of Verticillium dahliae from North American certified seed potatoes and characterization of strains by vegetative compatibility and aggressiveness. Am. J. Potato Res. 77:1-7.

30. Pegg, G. F., and Brady, B. L. 2002. Verticillium Wilts. CABI Publishing, CAB International, New York.

31. Powelson, M. L., and Rowe, R. C. 1993. Biology and management of early dying of potatoes. Annu. Rev. Phytopathol. 31:111-126.

32. Puhalla, J. E. 1979. Classification of strains of Verticillium dahliae based on heterokaryon incompatibility. Phytopathology 69:1186-1189.

33. Rowe, R. C., and Powelson, M. L. 2002. Potato early dying: management challenges in a changing production environment. Plant Dis. 86:1184-1193.

34. Schnathorst, W. C. 1981. Life cycle and epidemiology of Verticillium. Pages 81-111 in: Fungal Wilt Diseases of Plants. M. E. Mace, A A. Bell, and C. H. Beckman, eds. Academic Press, New York.

35. Termorshuizen, A. J., Davis, J. R., Gort, G., Harris, D. C., Huisman, O. C., Lazarovits, G. Locke, T., Melero-Vara, J. M., Mol, L., Paplomatas, E. J., Platt, H. W., Powelson, M. L., Rouse, D. I., Rowe, R. C., and Tsror, L. 1998. Interlaboratory comparison of methods to quantify microsclerotia of Verticillium dahliae in soil. Appl. Environ. Microbiol. 64:38463853 